\title{
The unfolding consequences of postponing routine dental care
}

\section{Explorando las consecuencias de posponer las atenciones odontológicas de rutina}

\author{
Duniel Ortuño Borroto', Juan Pablo Vargas Buratovic', Alonso Carrasco-Labra²
}

Keywords: COVID-19; oral diseases; dental care; oral health inequities; teledentistry.

Palabras claves: COVID-19, enfermedades bucales, cuidado dental, inequidades en salud bucal, teleodontología.

Submission date: 2020-11-04 - Acceptance date: 2021-06-09

The COVID-19 pandemic represents some of the most distressing challenges for health systems all over the world in the past decades, forcing clinicians to modify standards, prioritise treating conditions that require immediate care, and implement elements of remote attention in record time (Douglas et al., 2020). These challenges have also had an impact in the population's oral health.

The physical features of the dental office make it a potential high-risk setting for the transmission of SARS-CoV-2, mainly because of the proximity between members of the dental team and their patients (Peng et al., 2020). Also, clinicians often use aerosol-generating in dental care provision, which may play a role in further increasing the risk of airborne transmission in dental clinics (Epstein et al., 2020). Although the exact magnitude of risk of infection within dental offices remains unknown and new evidence needs to be generated. From the early stages of the pandemic, the dental community around the world decided to move towards postponing routine nonemergent procedures, following previous recommendations implemented in the last SARS and MERS outbreaks (Peng et al., 2020). This recommendation, formulated under a scenario of uncertainty regarding the potential benefits and harms, erred on the side of caution. It was based on placing a higher weight on patients' and clinicians' safety, from a value perspective. This restriction served two primary purposes. It gave the dental community precious time to gather available evidence, define new protocols, train dental personnel, and allow health systems to acquire new personal protective equipment (COVID-19 Dental Services Evidence Review Working Group, 2020). A second purpose was contributing to minimising the risk of transmission, particularly in areas of high community transmission rates. These measures, however, also come with a cost. Abruptly pausing dental care provision would have likely worsened the prognosis of several chronic oral diseases that otherwise could have been managed, with a negative impact on the overall dental morbidity and disease burden, that still needs to be measured.

The COVID-19 pandemic, in a global context of epidemics of oral diseases (Peres et al., 2019) will have significant short, medium, and long-term consequences, which will be an emerging challenge for health systems (figure 1). Although early on during the COVID-19 outbreak, the limitation of access to care could generate a volume of emergency consultations within a range to that observed before the pandemic, over time, an increase in the number of emergency consultations can be expected as a function of the lack of routine dental care (figure 1, red curve). During COVID-19 outbreaks, triage systems have been installed to balance the risk of viral exposure with the actual demand for care. In this stage, before dental attention, rapid antigen testing could be cost-effective, especially for the detection of asymptomatic cases in communities with moderate to a substantial viral transmission. As time passes, and during reopening periods, oral health providers may experiment a higher demand for care, in part, explained by a cumulative delay of non-urgent dental care (figure 1, green curve).

However, quantifying the long-term impact is problematic, as its effect is modulated by the role of the social and economic determinants of oral health (figure 1, blue curve). For example, untreated dental caries and periodontal disease would increase due to the

(1) Escuela de Odontología, Facultad de Medicina, Pontificia Universidad Catolica de Chile, Santiago, Chile.

(2) Department of Oral and Craniofacial Health Sciences, School of Dentistry, University of North Carolina at Chapell Hill.

Corresponding Author:drortuno@uc.cl. 
pandemic, with irreversible consequences for populations, including tooth loss and other undesirable effects of dental infections. In parallel, under this scenario, it is expected that the world would experience an increase in oral health inequities, especially in lowand middle-income countries (Marmot, 2020; Urström \& Tao, 2020).

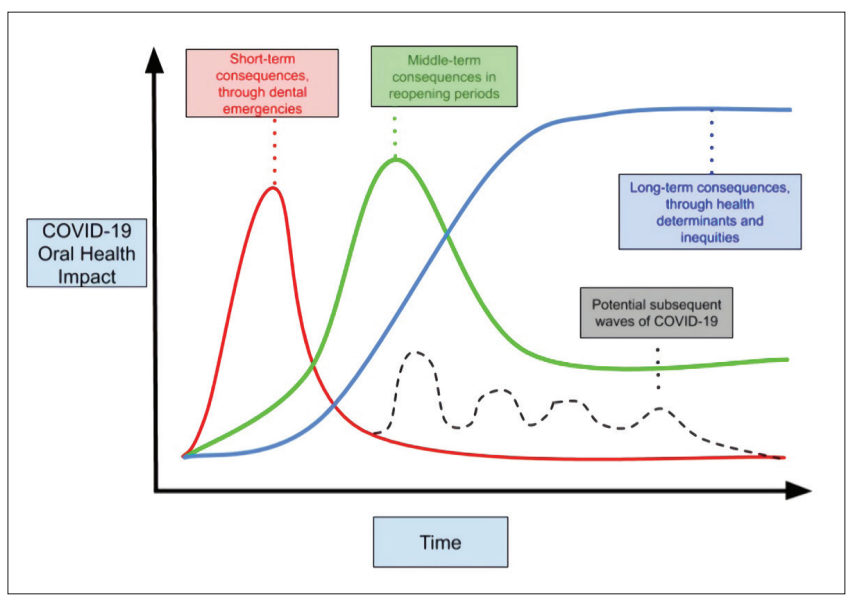

Figure 1: Short, Middle and Long-term consequences of COVID-19 in Oral health. It was adapted from UHC2030 International Health Partnership. Living with COVID-19:Time to get our act together on health emergencies and UHC.

The pandemic leaves a few lessons to the dental community worldwide. First, there is a need to refocus on health promotion and disease prevention, beyond the provision of dental fillings or other surgical interventions (Watt et al., 2019). Second, there is an opportunity to take advantage of technological tools that may facilitate the continuation of care until the next pandemic occurs, with emphasis on self-care, maintenance of oral hygiene, reduction of sugar consumption, and control of habits such as smoking, and self-examination. Teledentistry, including counselling and education, could help to mitigate the consequences of delayed face-to-face clinical care.

Moments of crisis create an environment conducive to change at all levels. This reflection calls for a change in the philosophy of dental care, with a higher emphasis on maintaining oral health, increasing access to care using teledentistry, and preparing dental health systems for the next pandemic.

Conflicts of interest: none to declare.

\section{References}

COVID-19 Dental Services Evidence Review Working Group. (2020). Recommendations for the re-opening of dental services: a rapid review of international sources. Accedido en from: https://oralhealth.cochrane.org/sites/oralhealth.cochrane.org/files/public/ uploads/covid19_dental_reopening_rapid_review_13052020.pdf el 15 de octubre de 2020.

Douglas, M., Katikireddi, S. V., Taulbut, M., McKee, M., \& McCartney, G. (2020). Mitigating the wider health effects of covid-19 pandemic response. BMJ (Clinical research ed.) 369, $\mathrm{m} 1557$.

Epstein, J. B., Chow, K., \& Mathias, R. (2020). Dental procedure aerosols and COVID-19. The Lancet. Infectious diseases 21, e73.

Marmot M. (2020). Society and the slow burn of inequality. Lancet 395, 1413-1414.

Peng, X., Xu, X., Li, Y., Cheng, L., Zhou, X., \& Ren, B. (2020). Transmission routes of 2019-nCoV and controls in dental practice. International journal of oral science 12, 9 .

Peres, M. A., Macpherson, L., Weyant, R. J., Daly, B., Venturelli, R., Mathur, M. R., Listl, S., Celeste, R. K., Guarnizo-Herreño, C. C., Kearns, C., Benzian, H., Allison, P., \&Watt, R. G. (2019). Oral diseases: a global public health challenge. Lancet 394, 249-260.

UHC2030 International Health Partnership. (2020). Living with COVID-19:Time to get our act together on health emergencies and UHC. Accedido en https://www.uhc2030.org/fileadmin/uploads/ uhc2030/Documents/Key_Issues/Health_emergencies_and_UHC/ UHC2030_discussion_paper_on_health_emergencies_and_UHC_-May_2020.pdf el 15 de octubre de 2020

Urström, B., \& Tao, W. (2020). Social determinants of health and inequalities in COVID-19. European journal of public health 30, 617-618.

Watt, R. G., Daly, B., Allison, P., Macpherson, L., Venturelli, R., Listl, S., Weyant, R. J., Mathur, M. R., Guarnizo-Herreño, C. C., Celeste, R. K., Peres, M. A., Kearns, C., \& Benzian, H. (2019). Ending the neglect of global oral health: time for radical action. Lancet 394, 261-272. 